\title{
REESCREVER A MORTE NA NARRATIVA INFANTIL PORTUGUESA CONTEMPORÂNEA
}

\author{
Ana Margarida RAMOS \\ CIDTFF - Universidade de Aveiro \\ anamargarida@ua.pt
}

\section{1}

\section{Introdução. Literatura e Morte}

Em diferentes culturas e em várias línguas, a presença da temática da morte na literatura de receção infantil em sido alvo de estudos, a maior parte sublinhando a emergência de um tema que já deixou de ser tabu. Associada à catarse ou mesmo a tendências conotadas com a biblioterapia, a temática tem conhecido, desde há décadas, diversos tipos de tratamento, incluindo por especialistas da saúde mental infantil. De forma sucinta, refira-se, no contexto francês, o estudo de Geneviève Arfeux-Vaucher (1994), La vieillesse et la mort dans la littérature enfantine de 1880 à nos jours, trabalho desenvolvido na esteira de outros que, desde a década de 70, foram trilhando este caminho, como Carol Romero (1974), Ruben Marshall (1975), Bailis (1978) e Davis (1986), só para dar alguns exemplos. A discussão sobre a presença e a pertinência (e a eficácia) do tratamento de temas considerados apoéticos, fora do eixo da tradicional positividade que caracteriza a literatura para a infância, é abundante (Gibson \& Zaidman, 1991; Carvalho, 2001) e quase sempre conclui com a ideia de que, enquanto sistema cada vez mais aberto e mais próximo do da literatura institucionalizada, não existem temas ou universos suscetíveis de não serem por ela revisitados e recriados. Num dos estudos mais recentes sobre esta questão, centrado na análise do papel desempenhado pela literatura junto das crianças que experimentam sentimentos de dor e perda, Angela M. Wiseman (2012) procede a uma extensa inventariação de publicações, produzidas no âmbito da psicologia, suscitadas pela questão da morte e da respetiva resposta infantil, elencando as diferentes reações registadas. No que diz respeito às respostas leitoras de álbuns sobre o tema, a investigadora defende que «reading and responding to literature has been identified as a powerful method for dealing with traumatic events, such as losing a loved one» (2012: 3), o que explica, por exemplo, o uso deste tipo de publicações em sessões de biblioterapia. A mesma investigadora ainda refere que o número crescente de publicações sobre o tema da morte permitiu já abordagens sistematizadoras (como a de Poling \& Hupp, 2008) das representações que o tema tem conhecido. Este último trabalho defende que os álbuns recriam uma variedade de reações emocionais face à morte, incluindo tristeza, negação, saudade e choque, mas parecem ignorar 
os factos biológicos que a ela surgem associados (irreversibilidade, disfuncionalidade, inevitabilidade e causalidade), apesar de a investigação psicológica já ter demonstrado «that the more children understand about biological factors, the less anxiety and fear they feel» (Wiseman, 2012: 4). As conclusões da análise levada a cabo pela investigadora de três álbuns sobre o tema da morte apontam para a ideia de que «children's picturebooks can provide a way to address and support children as they experience trauma and begin to understand the emotions surrounding their grief» (Wiseman, 2012: 11), na medida em que oferecem opções de identificação aos leitores, dando-lhes a conhecer diferentes (e mais ou menos próximas) experiências marcantes.

Teresa Colomer (2006) refere o tratamento reiterado desta questão como uma das novidades da produção literária infantil contemporânea, no seguimento das mudanças sociais verificadas nas últimas décadas e que a literatura infantil reflete de forma clara, sintetizando-as de forma perentória:

[...] en síntesis, puede decirse que en los libros actuales predomina un mundo presidido por niños y niñas urbanos, pertenecientes específicamente a clases medias, con acceso a formas culturales y artísticas prestigiosas, con padres que viajan, se divorcian y forman nuevas familias, situados en una sociedad que va evolucionando hacia la diversidad étnica y cultural y a los que llegan noticias de que en otros lugares existen problemas distintos, como el de las guerras (Colomer, 2006: 93).

A urbanidade e a agitação das sociedades contemporâneas, reguladas por ritmos ferozes e avassaladores, podem implicar uma valorização alternativa de um certo intimismo e introspeção que perpassa muitas das edições atuais. A aceitação da morte surge, segundo esta autora, exatamente nessa linha de pensamento:

[...] esos niños actuales, deben aprender también, ahora, a observar más allá de las formas trepidantes y caóticas de la sociedad de las prisas y el consumo que les envuelve, [...] de manera que puedan oír el silencio, distinguir lo que es superfluo, desprenderse de lo innecesario, gratificarse con la sencillez del trabajo bien hecho, identificar sus emociones y los sentimientos de los demás e iniciarse en el reconocimiento del amor y la aceptación de la muerte (Colomer, 2006: 93).

Ao nível das estratégias narrativas, a investigadora salienta a presença de dinâmicas de personagens mais complexas do que nas décadas anteriores, explorando a questão das relações interpessoais e, mesmo, intergeracionais. Neste sentido,

y también los ancianos [...], tan desplazados como los niños en los ritmos actuales de vida cumplen la función de aligerar su soledad. Los ancianos tienden a contemplarse ahora como "personas" más allá de su estricto papel familiar, y a mostrarse tanto en su vertiente humorística de gentes divertidas, con proyectos fabulosos, como en la más reflexiva de seres capaces de afrontar la decrepitud o la muerte con dignidad (Colomer, 2006: 94-95),

elementos que, como veremos, também marcam a produção narrativa portuguesa filiada neste tema. Pela sua simbologia, associada à ideia de fim, a morte possibilita recriações muito diversificadas, podendo surgir associada aos seres vivos, como os animais, as plantas ou o próprio homem, ou, em sentido metafórico, a ideias e conceitos, como a paz, uma amizade ou uma relação, assumindo conotações disfóricas e leituras angustiantes. A sua introdução, mesmo que sob a forma de eufemismos ou metáforas, no universo da literatura infantil, parece corresponder a uma certa necessidade de dar a conhecer a complexidade e até a vulnerabilidade que caracteriza a sociedade contemporânea. 


\section{Revisitação do tópico da morte em textos clássicos}

Alvo de distintas perspetivações, a morte entra nos textos narrativos destinados à infância através da literatura tradicional, onde ocupa lugar de relevo. Desde personagem, como a Comadre Morte do conhecido conto homónimo recolhido por Adolfo Coelho, a topos de assinalável recorrência, a morte também surge como elemento perturbador nos contos de fadas, associada ao desaparecimento de um progenitor, por exemplo, constituindo uma falta que, uma vez ocupada pela pessoa errada, vai originar uma sucessão de problemas, introduzindo uma dinâmica de desequilíbrio. Nestes textos, contudo, é apresentada com assinalável naturalidade, constituindo uma etapa obrigatória da vida humana. Vejase, nomeadamente, o incipit de alguns contos tradicionais, onde o pai, sentindo a morte aproximar-se, põe à prova os filhos para descobrir qual o mais digno herdeiro do seu legado. $\mathrm{O}$ incipit de História da Égua Branca (2000), de Eugénio de Andrade, inspirado na herança das narrativas populares, cumpre exatamente estes requisitos. Alice Vieira, na coletânea Contos de Grimm para Meninos Valentes (2009), opta por recriar um conjunto de textos da tradição popular percorridos pelas sugestões de medo e de violência, onde a morte ou, pelo menos, a sua ameaça está presente e condiciona a atuação das personagens, afastando-se de uma tendência da literatura contemporânea para o apagamento ou branqueamento destes dilemas existenciais. Apesar de ser eufemisticamente tratada, quando não censurada das publicações destinadas a crianças, a morte infantil, contudo, era já um motivo de impacto forte na obra de H. C. Andersen, ligada quer à sereiazinha, transformada em espuma, quer à menina dos fósforos, morta de frio na rua, abandonada e só, sonhando com o que não tem. Alvo de inúmeras adaptações e recriações, A Menina dos Fósforos constitui um dos mais célebres e mais tristemente comoventes contos de Hans Christian Andersen, sugerindo todo um ambiente de sofrimento, desamparo e dor que a maioria dos ilustradores tem dificuldade em recriar visualmente. Percebe-se, contudo, como o sonho é um complemento essencial da vida da protagonista e como a sua morte é interpretada enquanto passaporte para esse outro mundo, mais justo e mais afetuoso. Na esteira de outros contos do autor dinamarquês, esta é uma narrativa que não deixa de fazer refletir sobre a realidade dorida e sofrida de muitas crianças a quem a infância é roubada. Em A Sereiazinha (1995), é notável a forma como a personagem opta voluntariamente, num ato altruísta, pela sua morte em vez da do príncipe que ama, entregando-se ao seu destino: «Mais uma vez a sereiazinha olhou para o príncipe, com os olhos embaciados pela morte; depois, atirou-se para o mar, onde sentiu o corpo dissolver-se em espuma» (Andersen, 1995: 59). A morte, sinónimo do fim da existência humana da pequena sereia e da sua esperança de conquistar o afeto do príncipe, funciona também como fim do sofrimento da personagem, libertando-a definitivamente da dor.

O tema está ainda presente em muitos volumes traduzidos e editados em Portugal nos últimos anos, como O Sapo e o Canto do Melro (1998), de Max Velthuij; Querida Avó (2004), de Birte Müller; A história de Erika (2007), de Ruth Vander Zee e Roberto Innocenti; A Carícia da Borboleta (2008), de Christian Voltz; Fumo (2009), de Antón Fortes e de Joanna Concejo; ou O Coração e a Garrafa (2010), de Oliver Jeffers, só para dar alguns exemplos cuja análise não cabe nos limites deste breve estudo. 


\section{A morte na narrativa infantil contemporânea em língua portuguesa}

Na narrativa em língua portuguesa, a temática em causa, percorre um conjunto de textos e de autores significativos, sendo reescrita de formas diferentes por Matilde Rosa Araújo, Álvaro Magalhães, Maria Rosa Colaço, José Eduardo Agualusa, Luísa Dacosta, José Jorge Letria, Alice Vieira, António Mota ou Mia Couto, entre outros.

Associada à guerra, da qual é uma das principais consequências, ou à família, conotada com a perda de pessoas afetivamente próximas, a morte encontra tradução nos textos destinados aos leitores mais pequenos, conduzindo à reflexão, à interiorização, mas também ao diálogo, saindo do silenciamento e respondendo a inquietações comuns. Com maior ou menor carga simbólica ou alegórica, o tema permite, indiscutivelmente, aproximações de teor metafórico e lírico, contrariando a ideia da sua apoeticidade.

Como já tivemos oportunidade de tratar em outro momento (Ramos, 2007), o tratamento da guerra no âmbito da literatura para crianças e jovens tende a sublinhar as consequências pessoais e individuais dos conflitos, evitando que sejam tratados como acontecimentos longínquos e inconsequentes. Pela sua qualidade e pela originalidade da perspetiva narrativa selecionada, destaquese o caso de Comandante Hussi (2003), de Jorge Araújo e ilustrações de Pedro Sousa Pereira, obra que tematiza, sem pudor, a tragicidade da guerra e as suas consequências mais cruéis e aterradoras, ao mesmo tempo que narra uma insólita história de amizade entre um rapaz e a sua bicicleta, suportada pelos ideais da lealdade, da honra e, sobretudo, de uma inocência à prova de guerras. Os horrores dos conflitos militares, nomeadamente os fratricidas, convivem com o imaginário e o onírico, num universo onde os valores infantis ainda parecem estar muito presentes. Assim, os passeios de bicicleta de Hussi e os seus jogos de futebol depressa dão lugar às atividades de menino-soldado numa guerra na qual combatem o comandante Trovão e o brigadeiro Raio de Sol numa personificação do Mal e do Bem em confronto. Assim, mesmo apresentada como uma guerra justa - contra a tirania, a ditadura e a opressão - não deixa de fazer inúmeras vítimas e de exigir um preço muito elevado por parte do país e das populações:

[...] só ainda não esteve no Hospital, talvez porque não quer ver o que a guerra fez aos velhos que podiam ser o seu pai, sobretudo, aos outros meninos que tiveram menos sorte. São meninos a que a guerra ceifou pernas, vidas e família. Meninos a quem a guerra ceifou o futuro (Araújo, 2003: 58).

No caso português, até pela atualidade de que se reveste, a guerra colonial, às vezes em articulação com o 25 de Abril, sendo apresentada como uma das razões da exaustão do Estado Novo, surge recriada em vários textos de literatura infantil, como já pudemos demonstrar (Ramos, 2008). Trata-se do tema estruturante e eixo central do livro Lá longe onde o sol castiga mais - A Guerra Colonial contada aos mais novos (2008), de Jorge Ribeiro. A narrativa propõe uma recriação desassombrada, de nítido recorte catártico, a partir das memórias dos seus protagonistas, de um dos momentos mais trágicos da história portuguesa recente. Através dos relatos em primeira pessoa, são verbalizados acontecimentos escondidos ou silenciados daquele conflito traumático, como as doenças, o sofrimento, os crimes, as saudades, ilustrados com recurso a documentos reais, desde fotografias, a 
mapas, incluindo jornais, cartas e aerogramas, com o objetivo de reconstituir as memórias da participação portuguesa na guerra colonial. Instigados pela professora, os alunos descobrem, nas recordações dos seus avós, um passado esquecido e, muitas vezes, branqueado. O processo de revisitação parece atuar como catarse para os ex-combatentes e como descoberta para os adolescentes, confrontados com uma realidade simultaneamente próxima e distante. Sem tabus, a luz da memória ilumina algumas das sombras mais assustadoras da Ditadura em Portugal, falando, na primeira pessoa, dos combates, dos medos, das doenças, da resistência, do amor e da morte.

Igualmente, num cenário africano, ainda que fora do ambiente da guerra, desenrola-se a ação de O Beijo da Palavrinha (2008), de Mia Couto e Danuta Wojciechowska, texto já estudado noutro contexto (Ramos, 2012). Na obra para adultos deste escritor moçambicano a morte, nomeadamente a infantil, surge assiduamente, ligada às duras condições de vida daquele país. Refira-se, muito sucintamente, os casos de «O dia em que explodiu Mabata-bata» in Vozes Anoitecidas (1987) ou «O fazedor de luzes» in Na berma de nenhuma estrada e outros contos (2001), só para dar dois exemplos de contos onde as crianças enfrentam a realidade de morte - própria ou dos progenitores.

A morte, enquanto topos literário, percorre alguns dos contos de José Eduardo Agualusa insertos na coletânea premiada Estranhões \& Bizarrocos [estórias para adormecer anjos] (2000). Em «O pai que se tornou mãe», texto de ressonância lendária construído a partir do facto científico de que, na espécie do cavalo-marinho, é o macho que dá à luz as crias, a morte da fêmea, em resultado de uma doença desconhecida, surge associada a uma perda gradual de existência. A cor, a voz e as diferentes partes do seu corpo vão, progressivamente, desaparecendo, diluindo-se no espaço que rodeia a personagem:

Uma manhã Maria acordou doente. Tinha perdido o brilho. Ela que sempre tivera uma cor tão bonita -todo o seu corpo era amarelo iluminado- estava a ficar baça e transparente. Sentia-se muito leve, sentia que alguma coisa se apagava lentamente dentro dela. [...] À medida que as horas passavam Maria tornava-se menos existente -desaparecia. Primeiro desapareceu-lhe a cauda, as barbatanas perderam toda a cor, e até a sua voz ficou mais fraca, como se ela estivesse a afastar-se para muito longe (Agualusa, 2000: 49).

A seleção vocabular, nomeadamente dos adjetivos, exprime a evolução do processo e reforça o visualismo da cena, pelas referências cromáticas e sensoriais. Sem sugestões de dor ou de sofrimento físico visíveis, a aproximação da morte tem sobretudo implicações afetivas, uma vez que conduz ao afastamento definitivo do casal. A passagem dos ovos de Maria para Mário, última ação antes do suspiro final, constitui uma forma de recusa da morte na medida em que prolonga, numa nova geração e em novos seres, os limites da existência. Assim recriado, o ciclo da Natureza, na sua sucessão contínua de vida e de morte, parece ganhar novo sentido, religando o homem às suas origens. Em «A menina que queria ser maçã», a morte da protagonista, no final de uma vida plena, não é entendida como um final, mas corresponde a um novo começo. Trata-se, neste caso, da concretização do mais antigo sonho de Joaninha, ser maçã. Esse desejo, concedido por Deus, funciona como realização absoluta, ao mesmo tempo que, à semelhança do conto anterior, situa a ação narrada numa espécie de etapa específica de um ciclo orgânico e inquebrável, exemplo da extraordinária perfeição do Universo. O fragmento onde Joaninha exprime o seu desejo em tornar-se maçã tem correspondência com um 
outro, no final do conto, como o comprovam as alusões sensoriais, fechando um ciclo e iniciando outro: «Ela nem fazia caso. Quando crescesse havia de ser uma maçã, sim, uma maçã verdade, luminosa, tão perfumada como uma manhã de primavera» (Agualusa, 2000: 59), e

\footnotetext{
É preciso crescer muito para se ser uma boa maçã. Tu cresceste. Agora, sim, serás maçã. Alguns anos depois um menino descobriu no pomar da casa dos seus avós uma maçã de um brilho intenso. Cheirou-a: cheirava a manhãs lavadas, cheirava a primavera, era um cheiro que se colava aos dedos (Agualusa, 2000: 60).
}

Em A Girafa que comia estrelas (2005), igualmente de José Eduardo Agualusa, a morte, não sendo um elemento central da intriga, revela-se decisiva para a caracterização da heroína, a girafa Olímpia, uma vez que são as saudades da avó Rosália, já desaparecida, que a levam a passar a vida com a cabeça por entre as nuvens na esperança de a reencontrar:

A Avó Rosália, mãe de Dona Augusta, dissera-lhe que os anjos dormem nas nuvens. Também lhe dissera que quando as pessoas morrem se transformam em anjos. Dissera-lhe isto pouco antes de morrer. Por isso Olímpia passava o dia inteiro com a cabeça enfiada nas nuvens. Tinha saudades da avó (Agualusa, 2005: $\mathrm{s} / \mathrm{p})$.

Luísa Dacosta também não foge ao tema numa das suas obras mais emblemáticas, O Elefante cor-de-rosa (1974). Combinando uma diversidade de temas, como a passagem do tempo, o simbolismo da infância e do crescimento, com uma mensagem de índole ecológica e/ou ambiental, o texto aposta na construção de um cenário onírico e idílico, uma espécie de éden inicial no qual se começam a manifestar sintomas de decadência e morte. Em alguma medida, esse aparecimento da morte, do sofrimento e da degradação física parece ser uma revisitação do mito da queda/expulsão do paraíso ou do fim da Idade do Ouro, de que o fim da infância é também uma metáfora, quando a consciência do mal surge de forma mais efetiva e tangível.

Nos contos compilados em O Homem que não queria sonhar e outras histórias (1988), de Álvaro Magalhães, ecoam, de forma originalmente combinada, alguns dos temas centrais na poética deste autor, com particular destaque para a reflexão sobre a linguagem e a sua capacidade de construir e recriar mundos e outras realidades; os afetos; os sonhos e a dimensão onírica; a vida e a morte. Presente em dois dos breves contos, incluindo o que dá título ao livro, a morte surge como destino inevitável e inadiável, marco decisivo e definitivo da vida humana, cruzando-se com ingredientes importados do género fantástico. No caso do homem que não queria sonhar, depois de lhe ter sido concedida a concretização de todos os seus sonhos, sonha com a morte e, para a adiar, vê-se cativo de um sono contínuo e definitivo, afinal, outra forma de morrer também. Em «O livro que nunca acaba», a morte é novamente apresentada como um adormecimento definitivo, fim de uma história e início de outra, num ciclo contínuo e imparável de existências. A dimensão filosófica destes textos resulta da complexidade do tema e da abordagem proposta, questionadora e problematizadora do senso comum.

Álvaro Magalhães cruza o topos da morte com o do amor, obtendo narrativas de grande efeito dramático em Três Histórias de Amor (2003). Feitos de emoções fortes e de figurações muito originais, os enredos destas narrativas breves são orientados pela tematização do amor, da vida e da morte, corporizando, aliás, uma das tendências mais recorrentes da obra do autor. No primeiro conto, «O 
segredo da menina morta», dois jovens vivem um amor perturbado pela alma de uma menina que já partiu. João Maria, o protagonista, filho do guarda do cemitério, habituou-se a conviver com a morte e com os mortos com quem até dialoga. Apresentados como «tudo gente boa, inofensiva, muito comedida, a quem apenas faltava qualquer coisa, talvez um pouco mais de vida» (Magalhães, 2003: 9), os mortos testemunham os passeios e as aventuras mais ou menos solitárias do rapaz no cemitério, transformado, aos seus olhos, num «imenso e silencioso jardim perfumado» (Magalhães, 2003: 9) que, depois da hora do fecho, «lhe pertencia por inteiro» (Magalhães, 2003: 9). Conotados positivamente, os mortos e o cemitério criam expectativas originalmente diferentes das do senso comum, propondo um olhar diferente sobre a própria realidade. Desta feita, o convívio assíduo com a morte naturaliza-a e torna-a tão próxima e familiar que é possível a João Maria sentir-se levemente apaixonado por Inês, a menina morta há menos de um mês. Entendida como «apenas mais uma estação das suas vidas» (Magalhães, 2003: 10), a morte corresponde a um prolongamento, mais sossegado é certo, das vidas, uma espécie de repouso tranquilo e merecido em relação à agitação anterior. A perturbar a rotina das visitas diárias à campa de Inês, surge Sara, a menina que cativa o pequeno herói pelo «aroma a bolachas de baunilha acabadas de cozer que dela se desprendia» (Magalhães, 2003: 10), pelo brilho do olhar e pelo modo delicado como se move.

O afastamento gradual de Inês perturba-o e pesa-lhe tanto na consciência que, quando vislumbra o espírito da menina, teme que ela se tenha zangado. A realidade, como verifica, é diferente. Inês, apesar de morta, mantém-se presa ao mundo na tentativa de corrigir um erro infantil que pode custar a felicidade dos seus pais. Com a ajuda de João Maria, a rapariga pode partir sossegada e abandonar o limbo onde se encontra. Antes, porém, ocupando o corpo de Sara, despede-se do amigo com um beijo, saboreando essa última ligação aos sentidos e à vida. Espécie de requiem literário dedicado às vidas inocentes ceifadas demasiado cedo, o conto valoriza a existência vivida de forma intensa e plena.

A morte surge também em «Romance de Lucas e Pandora», conto publicado originalmente na obra coletiva Contos da Cidade das Pontes e posteriormente incluído no volume em análise, e no qual a ação é protagonizada por dois felinos. Depois de uma intensa vivida em conjunto, o casal apaixonado sente aproximar «o cheiro da morte» (Magalhães, 2003: 38) e procura descobrir o que o destino lhes reserva. $\mathrm{O}$ gato sábio confirma a existência do segredo: «há um segredo, pois. Chamam à morte malvada, maldita, macaca, mas ela tem outro nome, um nome secreto que ninguém conhece. Todos os gatos o sabem» (Magalhães, 2003: 39). Lucas descobrirá, finalmente, que os gatos vivem permanentemente presos ao ciclo da existência, renovando-se continuamente: «por temerem a morte é que os gatos correm, saltam, sofrem, lutam e amam. No fim de tudo, viveram. E estão sempre prontos para mais uma volta» (Magalhães, 2003: 41).

O terceiro e último texto do volume, intitulado «História do Velho e da sua linda nogueira», aproxima-se da parábola ou mesmo do mito e dialoga intertextualmente com o universo da tradição oral. Protagonizada por Miséria, um homem apaixonado pela sua nogueira, a narrativa cruza o imaginário do conto «Comadre Morte», com o qual partilha alguns elementos, pela força como a personagem, graças à astúcia, consegue enganar a Morte, adiando-a indefinidamente. Descobrirá, 
contudo, à sua custa, que o sofrimento de uma vida eterna é tão doloroso como o de uma existência demasiado breve. Miséria viverá, pois, para sempre, perseguindo os homens e impedindo-os de serem felizes:

[...] sempre houve miséria sobre a terra e, graças a mim, sempre haverá. E a culpa é minha. Enganando a morte, enganei-me a mim e fui condenado a pisar para sempre a terra. Enquanto o mundo for mundo, aqui estarei para contar esta história. E como é longa e negra e triste a eternidade (Magalhães, 2003: 66).

Para além dos topos do amor, presente no título da coletânea, a morte também percorre os três contos e assegura-lhes identidade e coesão. As diferentes figurações do tema dão conta do seu caráter multifacetado, além de elemento determinante da existência humana pela forma como a baliza, surpreende e engendra. A sua combinação com o amor coloca questões associadas à perenidade dos afetos, sugerindo, mais ou menos implicitamente, uma fruição intensa da vida.

Em alguns textos de Matilde Rosa Araújo pressente-se a presença da morte como realidade inevitável e próxima. A temática da velhice, por exemplo, é sintomática dessa consciência de aproximação do fim, como $O$ Capuchinho Cinzento (2005) deixa ver. Por seu turno, em O Gato Dourado (1977), volume clássico da literatura infantil portuguesa, a morte surge em dois contos, «O gato dourado»e «O passarinho viúvo», que recriam situações de perda afetiva superadas com coragem e determinação, recriando uma espécie de batalha interior entre a dor e a alegria pela continuação da vida. O protagonista do primeiro conto, companheiro inseparável de uma menina, abandona a vida entre um olhar nostálgico e uma despedida fugaz: «E uma manhã de Sol, em que a trepadeira estava mais azul, o gatinho dourado olhou a menina, com saudade. Olhou a trepadeira azul como se a visse pela primeira vez. E fechou os olhos. Os olhos dourados. Não os abriu mais. Morreu» (Araújo, 1977: 4). E a menina, inspirando-se na trepadeira que, tendo pertencido também ao gato, «continuava a dar flores [...], mais azul ainda» (Araújo, 1977: 4), «pegou na sua bicicleta e começou a correr pelo quintal [...] a fazer luz da sua tristeza» (Araújo, 1977: 4). A certeza de que a morte integra a vida como uma das suas etapas parece atenuar a dor da ausência e aumentar o desejo de viver plenamente. Em «O passarinho viúvo», o lamento feito canto do pássaro é interpretado como alegria pelos homens que, inspirados, parecem sofrer menos. Obrigação de coragem e de resistência, forma de também prestar homenagem à esposa morta, «os riscos do som do seu bico tomaram as cores todas do arco-íris» (Araújo, 1977: 18) e iniciam e anunciam, até, a primavera, metáfora universal da renovação da vida e da Natureza.

A morte percorre ainda textos de José Jorge Letria, nomeadamente as suas biografias ficcionadas como António o Principezinho (1993), inspirada no percurso de Antoine Saint-Exupéry, e Mouschi, o gato de Anne Frank (2002), obra que proporciona ao leitor, através de uma perspetiva original, um contacto efetivo com as consequências da $2^{\text {a }}$ Guerra Mundial e do Holocausto no universo quotidiano e privado de uma família e de uma adolescente, evidenciando aspetos esquecidos dos conflitos. Posteriormente, e num discurso muito pessoal, onde ecoam as memórias e as preocupações do escritor, veio a lume Avô conta outra vez (2008), uma narrativa versificada, de primeira pessoa, cujo texto constitui uma espécie de carta do narrador/avô para o neto. O narratário tem, por isso, um papel muito 
importante no texto, dividindo com o narrador o protagonismo. A relação de afeto entre ambos, dominada pela cumplicidade, pelo companheirismo e pela admiração mútuas, é o ponto de partida para este diálogo onde é visível também um certo lamento que resulta da constatação de que se a vida do neto está ainda a começar, a do avô, por seu turno, já vai numa fase mais avançada e pode ser pouco o tempo que resta a ambos para partilharem. É esse sentimento de proximidade do final da vida que conduz o narrador à necessidade de captar em livro, de modo a poder continuar a dialogar com o neto mesmo depois da sua morte, o deslumbramento que esta relação afetiva lhe traz e forma como o neto se tornou importante na sua vida, dando-lhe novos sentidos.

Em O mistério da coisinha azul (1989), de Maria Rosa Colaço, a autora parece recriar ou relembrar situações pessoais ligadas à sua experiência profissional de ensino à qual dedicou grande parte da sua vida ativa. Em contos como «Asinha de Gafanhoto» ou «Uma história com pombas de papel», percebemos a valorização do olhar infantil sobre o mundo e as coisas, mesmo as mais pequeninas e insignificantes, e a forma como as crianças exteriorizam afetos e emoções. Além disso, a professora é apresentada como intermediária entre o universo infantil e o adulto, revelando-se uma interlocutora preferencial da criança, que a vê como confidente e mesmo como cúmplice, até pela abertura que a caracteriza face ao maravilhoso e à sua erupção no seio do quotidiano. $\mathrm{O}$ conto «Recado com canário dentro» retoma um motivo recorrente na escrita da autora e que surge também em outros textos seus, não exclusivamente destinados ao público mais jovem. O leitor é confrontado com uma criança fascinada pelo ato de semear e pelo crescimento das plantas e que, depois da morte do seu canário, resolve semeá-lo também. O texto capta, com subtileza, a surpresa infantil perante a descoberta da morte, depressa transformada em espanto doloroso:

[...] o que vou contar a seguir foi para mim muito triste e difícil de entender. É que um dia, sem esperar, caiu granizo. $\mathrm{O}$ canário, que estava lá fora, na gaiola junto à janela, a apanhar os raios de sol do primeiro dia de primavera, não resistiu ao frio daquelas pedras de neve. Morreu. Logo, logo, não percebi bem o que acontecera. Mas, perturbada com a terrível revelação, depressa descobri que alguma coisa diferente, silenciosa e inesperada pode interromper a vida (Colaço, 1989: 24-25).

As mais diversas e insólitas sementeiras da narradora metaforizam, no fim de contas, a sua esperança ilimitada no renascimento do mundo aqui associado a uma primavera simbólica. A morte é, pois, pretexto para repensar e sonhar a vida, como acontecera com a obra mais conhecida da autora, $O$ Espanta-Pardais (1961). Assumindo-se como intemporal, a narrativa contempla uma leitura fortemente simbólica e poética, estando assente numa dinâmica metafórica particularmente consistente. Para além de defender o direito ao sonho e a exaltação da amizade, texto recria ainda do tema da morte e do sofrimento, mas também da superação e da recompensa, apostando numa leitura de esperança e de renascimento: «Nunca morremos. E todos os dias sonhamos» (Colaço, 1961: 52).

De forma diferente, porque estruturada a partir do modelo da ficção científica, a novela $O$ Planeta Branco (2005), de Miguel Sousa Tavares, constitui um exemplo de texto onde se cruzam algumas das questões mais atuais e pertinentes, relacionadas com a relação do homem com o meio ambiente, a sua destruição e as suas consequências. Situando a ação num tempo futuro, o narrador apresenta uma tentativa de resolver o problema do desequilíbrio ambiental, ao mesmo tempo que 
promove a reflexão sobre um conjunto de questões inquietantes como a morte e a vida depois dela, o envelhecimento e a existência de vida em outros planetas. Trata-se de, a partir de uma situação ficcional ocorrida num futuro mais ou menos longínquo, verosímil pela contextualização científica apresentada, subsidiar a reflexão e a ação no momento presente, valorizando a importância da salvaguarda e proteção dos recursos naturais finitos, ao mesmo tempo que é sublinhada a confiança na espécie humana e na sua extraordinária capacidade de superação em momentos cruciais da sua História e evolução. No estranho planeta branco, habitado pelos mortos, guardam-se segredos sobre a vida e sobre o futuro que, segundo o seu guardião, devem permanecer desconhecidos porque «é assim que está escrito: o homem nunca deve saber o que existe depois da vida. Deve viver a vida como uma coisa única e preciosa. Um presente dos deuses» (Tavares, 2005: 77). A vida, no seu ciclo de nascimentos e mortes, cumpre-se e prolonga-se para lá dos tempos, sob diferentes formas. A narrativa propõe uma leitura, simultaneamente metafísica e biológica dessa existência, inclusivamente na sua extensão para além da morte, seja habitando o planeta Branco, seja sob a forma de estrelas:

É uma coisa natural: a vida é natural e a morte é natural. Tudo o que está vivo à face da Terra - os animais, as plantas, os rios, as florestas, os homens - um dia morre e dá lugar a outros, que, por sua vez, vão viver e vão morrer. E tudo continua para sempre (Tavares, 2005: 72).

\section{Conclusões}

A literatura para a infância contemporânea integra, cada vez mais assiduamente, temas complexos e realidades problemáticas, retirando do silêncio questões como o sexo, a guerra ou a própria morte. Teresa Colomer afirma que

\footnotetext{
más allá de la anulación de las prohibiciones implícitas, los nuevos temas de la literatura infantil significarán especialmente una invitación hecha al lector para que considere el conflicto como una parte inevitable de la propia vida. Y, así, el tema del enfrentamiento al dolor tomará cuerpo en sus formas más variadas: la enfermedad, la locura, la muerte, las minusvalías, la incomunicación, etc. (Colomer, 2008: 111).
}

Sem pretensões de exaustividade, procurou-se que os textos selecionados dessem conta da variedade de tratamento que a temática da morte conhece na narrativa contemporânea em língua portuguesa, possibilitando à criança o contacto com uma realidade considerada perturbadora, traumática ou mesmo chocante. Promovendo um certo apaziguamento, seja pela via metafórica ou pela transposição da morte para animais e outros seres vivos, os textos procuram ajudar a lidar com a perda, apelando à verbalização de emoções e sentimentos.

\section{Referências bibliográficas}

\section{Obras analisadas}

AgualusA, José Eduardo (2000): Estranhões \& Bizarrocos [estórias para adormecer anjos]. Lisboa, Dom Quixote (ilustrações de Henrique Cayatte).

- (2005): A Girafa que Comia Estrelas. Lisboa, Dom Quixote (ilustrações de Henrique Cayatte). 
Andersen, Hans Christian (1995): A Sereizinha. Porto, Afrontamento (ilustrações de Manuela Bacelar).

ARAúJo, Jorge (2003): O Comandante Hussi. Lisboa, Quetzal (ilustrações de Pedro Sou sa Pereira). Araújo, Matilde Rosa (1977): O Gato Dourado. Lisboa, Livros Horizonte (ilustrações de Maria Keil). ColAÇO, Maria Rosa (1961): O espanta-pardais. Lisboa, Sociedade de Expansão Cultural. (1989): O Mistério da coisinha azul. Lisboa, Plátano (ilustrações de Ana Duarte de Almeida).

Couto, Mia (2008): O Beijo da Palavrinha. Lisboa, Caminho (ilustrações de Danuta Wojciechowska). LETRIA, José Jorge (2008): Avô, conta outra vez. Porto, Ambar (ilustrações de André Letria).

MAGAlHÃES, Álvaro (1988): O Homem que não queria sonhar e outras histórias. Porto, ASA (ilustrações de António Modesto).

- (2003): Três Histórias de Amor. Porto, ASA (ilustrações de António Modesto).

RIBEIRO, Jorge (2008): Lá longe onde o sol castiga mais - A Guerra Colonial contada aos mais novos. Porto, Calendário.

TaVAres, Miguel Sousa (2005): O Planeta Branco. Cruz Quebrada, Oficina do Livro (ilustrações de Rui Sousa).

\section{Bibliografia Passiva}

ARFEUX-VAUCHER, Geneviève (1994): La vieillesse et la mort dans la littérature enfantine de 1880 à nos jours. Paris, Imago.

BAILIS, L. A. (1978): «Death in children's literature: A conceptual analysis», Omega, Journal of Death and Dying, 8, pp. 295-303.

CARvalHo, Cláudia Ezídgia de (2001): «A Presença da morte na literatura infantil do Brasil», in Anais do Congresso de Leitura do Brasil 12, Campinas, ALB, 1 CD.

COLOMER, Teresa (2006): «La educación sentimental en los ábumes infantiles actuales», en VIANA, Fernanda Leopoldina, CoQuet, Eduarda, \& MARTINs, Marta, Actas do $6^{\circ}$ Encontro Nacional $\left(4^{\circ}\right.$ Internacional) de Investigação em Leitura, Literatura Infantil e Ilustração, Braga, Universidade do Minho, pp. 88-97.

- (2008): Introducción a la literatura infantil y juvenil. Madrid, Editorial Síntesis.

DAVIS, G. L. (1986): «A content analysis of fifty-seven children's books with death themes», Child Study Journal, 16, pp. 39-54.

GIBSON, Lois Rauch, \& ZAIDMAN, Laura M. (1991): «Death in Children's Literature: Taboo or Not Taboo?», Children's Literature Association Quarterly (16-4), pp. 232-234

MARSHALL, Ruben (1975): «The concept of Death in Children's Literature», paper presented at de Annual Meeting of the Illinois Association of School Librarians (Springfield, Illinois, April 1012, 1975), en http://eric.ed.gov/?id=ED111431.

Poling, Devereaux A., \& HuPP, Julie M. (2008): «Death Sentences: A Content Analysis of Children's Death Literature». The Journal of Genetic Psychology, 169(2), pp. 165-176. 
162 Tropelías. Revista de Teoría de la Literatura y Literatura Comparada, 23 (2015) Ana Margarida Ramos

Ramos, Ana Margarida (2007): Livros de Palmo e Meio - Reflexões sobre literatura para a infância. Lisboa, Caminho.

(2008): «Memórias da Revolução de Abril na Literatura para a Infância: diferentes formas de contar a mesma história», en VIANA, Fernanda Leopoldina, COQUET, Eduarda, \& MARTINS, Marta, Actas do $6^{\circ}$ Encontro Nacional (4 $4^{\circ}$ Internacional) de Investigação em Leitura, Literatura Infantil e Ilustração (Braga, Universidade do Minho, Outubro 2006), Braga, Universidade do Minho, pp. 130-140.

(2012): Tendências contemporâneas da literatura portuguesa para a infância. Porto, Tropelias \& Companhia.

ROMERO, Carol E. (1974): The treatment of Death in Contemporary Children's Literature, Master Thesis, Long Island University.

Wiseman, Angela M. (2012): «Summer's End and Sad Goodbyes: Children's Picturebooks About Death and Dying», Children's Literature in Education, en http://link.springer.com/article/ 10.1007\%2Fs10583-012-9174-3. 